\title{
Erythromelalgia in the pediatric patient: role of computed-tomography-guided lumbar sympathetic blockade
}

This article was published in the following Dove Press journal: Journal of Pain Research

18 October 2016

Number of times this article has been viewed

\author{
Anjana Kundu' \\ Mahmood Rafiq ${ }^{2}$ \\ Patrick S Warren ${ }^{3}$ \\ Joseph D Tobias ${ }^{2,4}$ \\ 'Department of Anesthesiology, \\ Dayton Children's Hospital, Dayton, \\ ${ }^{2}$ Department of Anesthesiology \\ and Pain Medicine, ${ }^{3}$ Department of \\ Radiology, Nationwide Children's \\ Hospital, ${ }^{4}$ Department of \\ Anesthesiology and Pain Medicine, \\ The Ohio State University College of \\ Medicine, Columbus, $\mathrm{OH}$, USA
}

\begin{abstract}
Erythromelalgia (EM) is an uncommon condition characterized by erythema, increased skin temperature, and burning pain, most frequently occurring in the lower extremities. The pain is generally very severe and treatment can be extremely challenging, especially in the pediatric and adolescent population. We report a series of three cases of primary EM in pediatric patients involving the lower extremities, refractory to medical treatment that responded favorably to computed-tomography-guided lumbar sympathetic blockade. There was a significant improvement in pain scores, quality of life, and overall function as well as decreased analgesic requirements. Lumbar sympathetic blockade should be considered as a therapeutic modality in pediatric and adolescent patients with EM who are refractory to other treatments.

Keywords: primary erythromelalgia, secondary erythromelalgia, computed tomography guided, lumbar sympathetic blockade
\end{abstract}

\section{Introduction}

Erythromelalgia (EM) is a chronic, debilitating condition characterized by erythema, warmth, and severe burning pain primarily involving the distal extremities. ${ }^{1}$ However, there have been case reports suggesting atypical and less common presentations of EM with involvement of face, neck, ears, or the perineum. ${ }^{2-5}$ The overall age- and sex-adjusted incidence is 1.3 per $100,000 .{ }^{1,6}$ The sex-adjusted incidence rates are 2.0 (1.2-2.7) per 100,000 females and $0.6(0.1-1.1)$ per 100,000 males. However, the incidence has been reported to be as high as three of 5,000 patients referred to a pain clinic. ${ }^{7}$ EM was first described in 1872 by Mitchell $^{8}$ and later categorized as a primary (idiopathic) or secondary form in 1938 by Smith and Allen. ${ }^{9}$ While the underlying etiology remains unknown, proposed pathophysiologic mechanisms include increased blood flow, microvascular shunting, increased local metabolism, and small fiber neuropathy. ${ }^{9-14}$ EM may be an isolated, primary condition or can be secondary to comorbid conditions. Primary EM may occur sporadically or be inherited with an autosomal dominant pattern with mutations in the $S C N 9 A$ gene, which encodes the sodium channel protein, $\mathrm{Na}(\mathrm{v}) 1.7$ subunit. ${ }^{13-17}$

Pain in EM is precipitated by increases in temperature and by exercise. Patients may obtain temporary relief by immersing the affected extremity in cold water, although longterm pain control is often refractory to treatment. The variety of proposed pathophysiologic mechanisms responsible for EM explain, in part, the large number of therapies that have been advocated as well as the variable responses to these clinical treatments. For many patients, multiple analgesic medications are tried, without adequate symptomatic
Department of Anesthesiology and Pain Medicine, Nationwide Children's Hospital, 700 Children's Drive,

Columbus, $\mathrm{OH} 43205$, USA

Tel + I 6147224200

Fax +l 6147224203

Emaildrmahmoodmalik@yahoo.co.in 
relief. Medications that have been anecdotally reported to be effective in some individuals include aspirin, misoprostol, serotonin-norepinephrine reuptake inhibitors and selective serotonin reuptake inhibitors, gabapentinoids, sodium channel blockers, carbamazepine, tricyclic antidepressants, calcium antagonists, magnesium, sodium nitroprusside infusion, and cyclosporine. Sympathetic blockade, surgical sympathectomy, and epidural infusions of local anesthetic agents with opiates have also been used with varying degrees of success. Although the use of sympathetic blockade in secondary EM has been described in adults, there are very few reports of its use in primary EM in children and adolescents. We present three cases of primary juvenile EM in which lumbar sympathetic blockade (LSB) proved to be effective in reducing the frequency and severity of pain episodes and improving the patients' quality of life. In this article, the potential role of LSB in treating pain related to EM is discussed, the technical aspects of the modality are presented, and reports of its use in the adult population are reviewed.

\section{Case series}

Review of these cases and presentation in this format was approved by the institutional review board of Nationwide Children's Hospital (Columbus, OH, USA). Our Institutional Review Board does not require us to obtain patient consent for case reports/series.

\section{Patient I}

A 5-year-old, $14.8 \mathrm{~kg}$ boy was diagnosed with EM and primary hypertension 3 months prior to consultation by the pain management team. He had been symptomatic since the age of 2 years with restless leg syndrome. Consultation with the pediatric rheumatology service was sought when his lower extremities became progressively more painful, there was an increase in the restlessness of his legs, and erythema associated with color changes of the skin in the feet and lower legs appeared. No secondary cause of EM was found. Laboratory evaluation was normal, including a complete blood count, basic metabolic panel, liver function tests, antinuclear antibodies, and C-reactive protein. Genetic workup revealed $S C N 9 A$ gene mutation of the voltage-gated sodium channels. He had recently been admitted to the hospital twice for pain management. His symptoms had been refractory to multiple medical management modalities and interventions, including gabapentin, pregabalin, mexiletine, clonidine, topical ketamine, and amitriptyline cream as well as intravenous (IV) lidocaine, ketamine, and nitroprusside infusions. At the time of consultation, his home medications included mexiletine $30 \mathrm{mg}$ per os (PO) twice a day (bid), gabapentin $60 \mathrm{mg}$ PO three times a day, and prednisolone $8 \mathrm{mg}$ PO once a day. Intermittently, his pain would become severe and his feet would be very hot, edematous, and red. His pain was relieved by placing his feet in cool water or using a fan to cool his feet. He was spending an increasing amount of time with his feet in the bath tub and had developed skin breakdown. He had been evaluated by nephrology for hypertension and started on clonidine $(50 \mu \mathrm{g})$ by mouth three times a day. Diagnostic evaluation for secondary etiologies of hypertension was negative. Pain in his feet had been persistent with multiple daily acute, severe episodes of pain. Pain intensity was rated as high as 10 on a $0-10$ scale. He had cold, erythematous discoloration with skin breakdown on both lower extremities (Figure 1). Muscle atrophy was noted in both calf muscles. Sensory examination was normal with no allodynia or hyperalgesia. His quality of life had been severely impaired and he spent most of the time in the bath tub or wearing cooling boots. His sleep had been severely affected by pain and he slept with cold wraps on his feet. There was a lack of response from all the medical interventions, with distressing adverse effects related to the medications. He was referred to the pediatric pain clinic, and following evaluation and a discussion with his family, he was scheduled to undergo computed tomography (CT)-guided LSB. After obtaining a written parental consent, the procedure was performed under general anesthesia with the patient in the prone position.

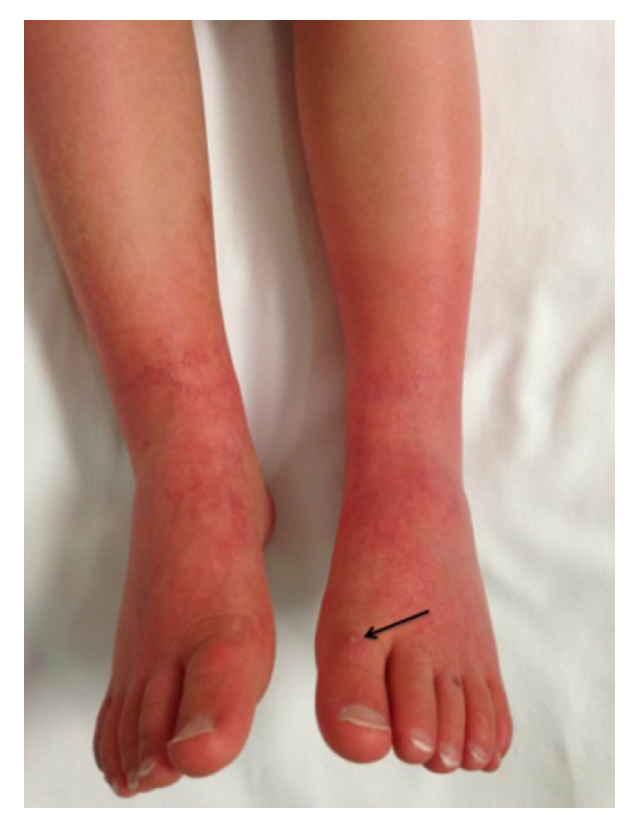

Figure I Photograph of the lower extremities of patient I with primary EM. Note: The distal lower extremities are erythematous and swollen and feet with a small blister (arrow) on the left great toe. Abbreviation: EM, erythromelalgia. 


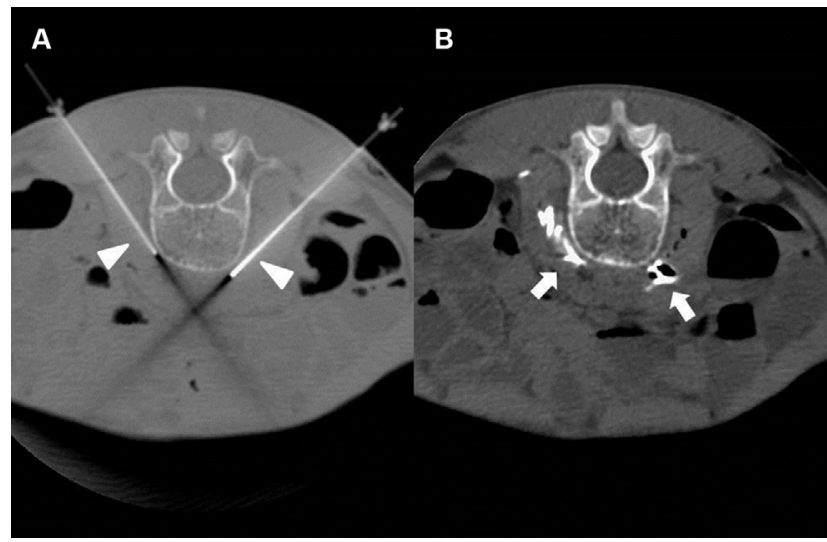

Figure 2 CT fluoroscopy images patient I

Notes: (A) Axial CT fluoroscopy image obtained at the level of the L3 vertebral body shows simultaneous placement of $21 \mathrm{G} 15 \mathrm{~cm}$ needles (arrowheads) into the prevertebral space via a posterior approach. (B) The final axial CT image obtained at the same level following drug and contrast administration shows dispersion of contrast material (arrows) in the prevertebral space corresponding to the location of the lumbar sympathetic chains.

Abbreviation: CT, computed tomography.

Under intermittent $\mathrm{CT}$ fluoroscopy, $15 \mathrm{~cm} 21 \mathrm{G}$ Chiba needles were advanced in tandem via bilateral posterior approaches through the psoas muscles. The needle tips were positioned just anterior to the $\mathrm{L} 3$ vertebral body in the expected location of the lumbar sympathetic chains (Figure 2A). Then, $5 \mathrm{~mL}$ of $0.2 \%$ ropivacaine, $30 \mathrm{mg}$ clonidine, and $20 \mu \mathrm{g}$ triamcinolone were injected after negative aspirate for blood. Each needle was then flushed with $0.5 \mathrm{~mL}$ of saline, and a small amount of contrast was injected to document appropriate drug dispersion. Contrast distribution along the lumbar sympathetic chain was confirmed with $\mathrm{CT}$ imaging (Figure 2B). Immediately following the placement of the sympathetic blockade, there was increased temperature of both lower extremities, with visible vasodilation and decreased discoloration of the lower extremities (Figure 3). This resulted in an improvement in his pain symptoms, improved sleep, and no flare-ups for $\sim 3$ weeks. There were some complaints of residual pain on the right side, and a repeat LSB was performed 4 weeks after the first blockade. After the second LSB, he was discharged home on oxycodone $(1.5 \mathrm{mg}$ by mouth every 4 hours as needed for pain), but he did not require any doses. With his hospitalizations, he had developed extreme anxiety related to the hospital and medical professionals. To manage his anxiety, he was started on clonazepam $0.125 \mathrm{mg}$ PO at bedtime as needed and escitalopram $7.5 \mathrm{mg}$ PO once a day. In addition, carbamazepine was gradually titrated to $50 \mathrm{mg}$ PO bid in between the two LSB procedures. Acupressure with ear magnets was also instituted. Two weeks after the second LSB, the pain had decreased significantly. His appetite improved, and he gained $\sim 5$ pounds. He was more playful and was sleeping well. The swelling in his feet decreased, and his skin

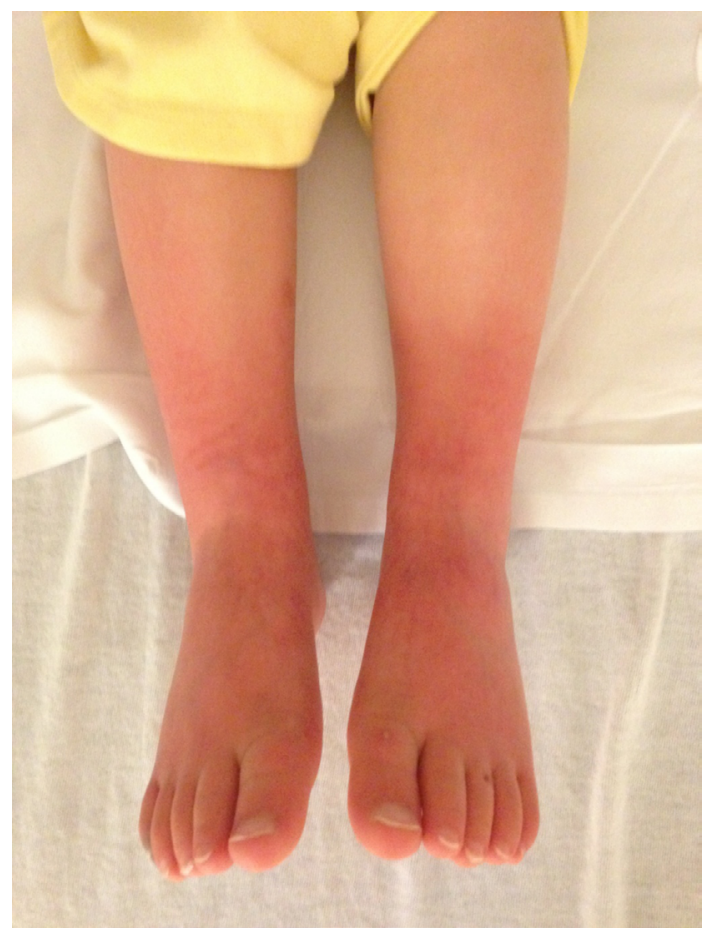

Figure 3 Photograph of the lower extremities of patient I demonstrating decreased erythema and discoloration immediately after the CT-guided LSB.

Abbreviations: CT, computed tomography; LSB, lumbar sympathetic blockade.

looked increasingly better with no further skin breakdown. The clonazepam was tapered and discontinued. He also started engaging in trips outside the house and enrolled in piano lessons and swimming. He completely stopped the use of cold wraps around his feet and legs. He has not required hospitalization since his second LSB $>9$ months ago.

\section{Patient 2}

A 15 -year-old, $52.3 \mathrm{~kg}$ adolescent male was diagnosed with EM based on an initial presentation with bright red, painful, and edematous hands that responded only to cold water immersion, later progressing to primarily involve his lower extremities. The laboratory workup including a complete blood count, basic metabolic panel, liver function tests, antinuclear antibodies, and C-reactive protein was normal. Genetic workup did not reveal gene mutations. His initial presentation included aching, burning, sharp, stabbing, and stinging pain in his hands associated with intermittent redness and swelling, mostly occurring when waking up in the morning. The initial episodes were brief, requiring only ibuprofen. Aggravating factors included sitting, stress, and heat, while relieving factors included holding his hands under cool water, walking, running, lifting, cold temperatures, relaxation, massage, physical therapy, and medications. His pain had increased gradually over 8 months becoming constant with an intensity of $10 / 10$. The pain escalated to the point 
of requiring hospitalization for pain control. In addition, he had decreased appetite with weight loss, sleep disturbance, and developed a mood disorder with anxiety and depression. He was hospitalized for nearly 3 weeks for a pain crisis and received daily opioids via a hydromorphone patient-controlled analgesia device along with several other adjuvant medications (methadone $2.5 \mathrm{mg}$ PO bid, indomethacin $75 \mathrm{mg}$ PO bid, clonidine $0.3 \mathrm{mg}$ PO once daily, cyclobenzaprine $10 \mathrm{mg}$ three times a day, mexiletine $200 \mathrm{mg}$ PO bid, pregabalin $200 \mathrm{mg}$ PO bid, amitriptyline $25 \mathrm{mg}$ once daily, diphenhydramine $25 \mathrm{mg}$ PO four times a day as needed, and cyproheptadine $2 \mathrm{mg}$ PO three times a day) with limited success. His upper extremities were cool to touch and showed mild mottling. On neurological examination, no findings of allodynia, hyperalgesia, dysesthesia, or dystrophic changes were noted. He was eventually discharged home with recommendations for outpatient follow-up with physical and occupational therapy and the pain management clinic. His discharge medications included oxycodone $15 \mathrm{mg}$ PO every 6 hours, amitriptyline $25 \mathrm{mg}$ PO at bedtime, clonidine $0.3 \mathrm{mg}$ PO at bedtime, duloxetine $60 \mathrm{mg}$ PO every morning, pregabalin $200 \mathrm{mg}$ PO bid, and mexiletine $200 \mathrm{mg}$ PO bid. He required readmission to the hospital 3 weeks later due to severe pain in both of his lower extremities which was intolerable. His pain was refractory to medical management. After a discussion with the patient and his family, a bilateral LSB was planned. The procedure was performed, after obtaining assent from the patient and a written consent from parents, in a similar fashion to that described in case 1 including the use of general anesthesia. Under intermittent CT fluoroscopy, $15 \mathrm{~cm} 21 \mathrm{G}$ Chiba needles were advanced in tandem via bilateral posterior approaches through the psoas muscles and the needle tips were positioned just anterior to the L4 vertebral body in the expected location of the sympathetic chains. Following the needle placement, $0.5 \mathrm{~mL}$ of iodinated contrast was injected through each needle to confirm the correct placement (Figure 4). A mixture of $0.2 \%$ ropivacaine $(10 \mathrm{~mL})$, clonidine $(50 \mu \mathrm{g})$, and triamcinolone (40 mg) was injected at the level of the L4 lumbar sympathetic ganglion on each side. A final CT scan of the lumbar spine was performed showing no evidence of acute complications and dispersion of contrast in the expected location of both sympathetic chains. The patient had a decrease in the pain intensity immediately post procedure as evidenced initially by decreased opioid analgesic requirements as well as improved pain scores. During the follow-up, 5 weeks after the LSB, the patient reported reduced pain. He now required only one oxycodone a day, if at all. He spent more time with family and in bike riding, swimming, walking, and doing chores around

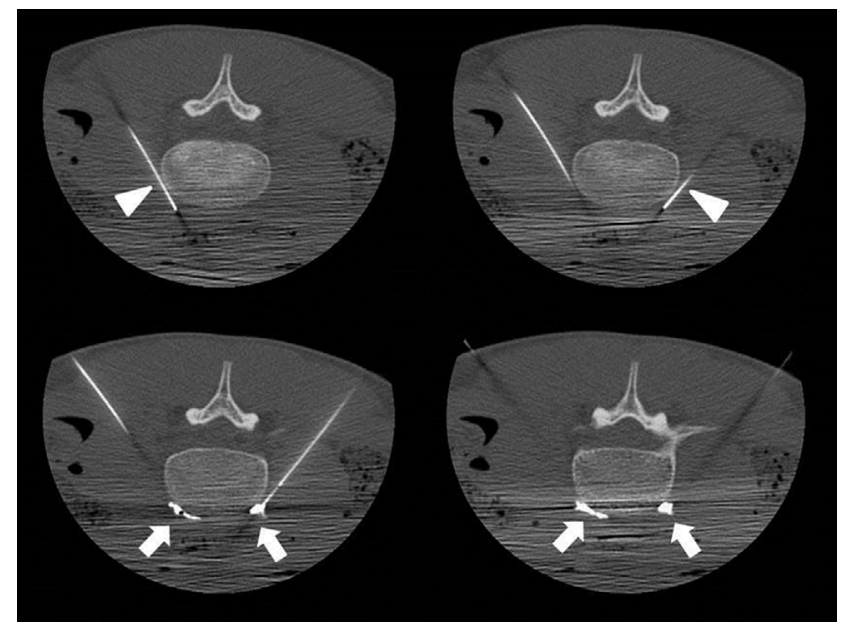

Figure 4 Axial CT fluoroscopy images patient 2

Notes: Axial CT fluoroscopy images obtained during LSB showing sequential placement of $21 \mathrm{G}, 15 \mathrm{~cm}$ needles (top left and top right, arrowheads) into the prevertebral space at the $L 4$ vertebral level. Images obtained following administration of medication and contrast through each needle show even dispersion of the agents in the prevertebral space adjacent to the lumbar sympathetic chains (bottom left and bottom right, arrows).

Abbreviations: CT, computed tomography; LSB, lumbar sympathetic blockade.

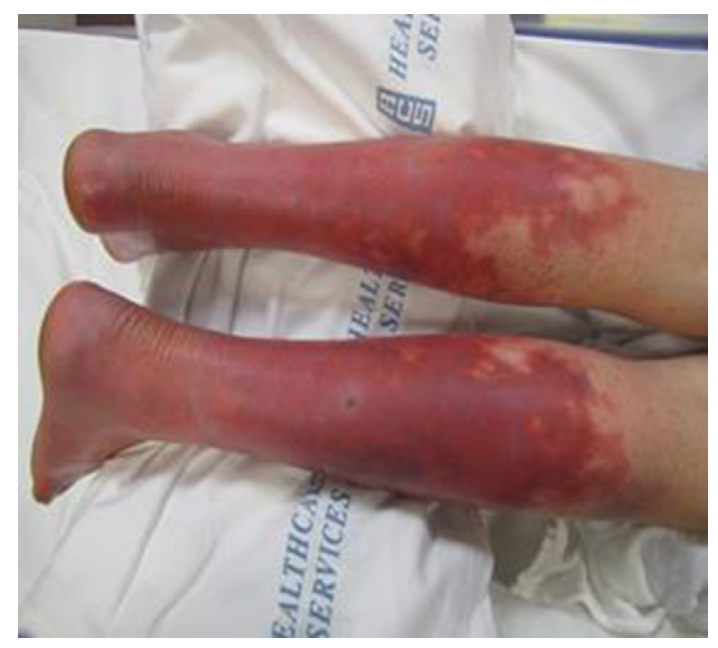

Figure 5 Photograph of the lower extremities of patient 3 with primary EM, demonstrating erythema and discoloration.

Abbreviation: EM, erythromelalgia.

the house. His mood improved; he was feeling more upbeat and was planning on resuming his school. He was sleeping more comfortably, eating better, and gaining weight.

\section{Patient 3}

A 17-year-old, SCN 9A-positive female adolescent, symptomatic from her first year of life, was diagnosed with EM at 5 years of age. At the time of presentation, she was hypertensive and her calves and feet were warm, tender, and discolored, but her hands and face were unaffected (Figure 5). The initial therapies tried to manage her symptoms included Aveeno baths, aspirin, cetirizine, amitriptyline, and 
hydroxyzine. Her hypertension remained well controlled on phenoxybenzamine until 10 years of age when her EM became more symptomatic. She was then effectively treated with gabapentin, amlodipine, and labetalol for the next 2 years. Subsequently, the pain in her lower extremities became more refractory and she spent increasing amount of time with her feet immersed in water and with cooling fans. This resulted in breakdown of her skin involving her lower extremities and resultant ulcers, requiring hospitalization for treatment of the lower extremity ulcers and pain. The treatment consisted of IV antibiotics and sodium nitroprusside infusion, without any improvement in her pain. She was referred to the pain clinic, where additional therapies were tried including IV lidocaine, mexiletine, phenoxybenzamine, clonidine, and increasing doses of gabapentin with variable therapeutic response. At the age of 16 years, her pain was poorly controlled on gabapentin and clonidine. Her calves and feet were purplish red and edematous, the skin was excoriated, and her burning pain would reach an intensity of 10 on a numeric rating scale of $0-10$. She was unable to tolerate shoes, and she kept her feet elevated with an electric fan blowing air on them. School attendance was greatly impaired as were her and her family's participation in social activities. Considering the lack of response to medical therapies, an LSB was planned. A written informed consent from parents and a verbal assent from the patient were obtained. After the induction of general anesthesia, the patient was placed in prone position. Skin markings for needle entry site and to define the needle trajectory were made bilaterally using a radiographic grid (Figure 6) at the L4 level. Under intermittent CT fluoroscopy, $22 \mathrm{G}, 13 \mathrm{~cm}$ Whitacre needles were inserted in tandem via a posterior approach bilaterally (Figure 7). The needle tips were positioned anterior to the L4 vertebral bodies in the expected location of the lumbar sympathetic chains. Needle placement was confirmed using $0.2 \mathrm{~mL}$ contrast iopamidol (Isovue- $\mathrm{M}^{\circledR} 200$ ). A mixture of

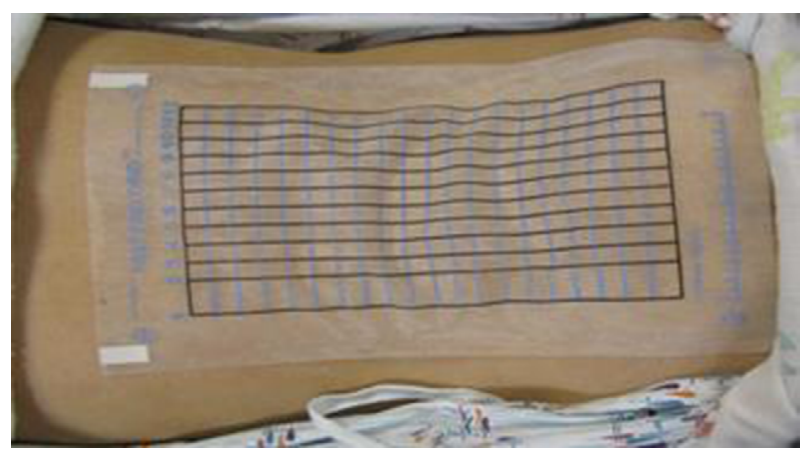

Figure 6 Radiographic grid placed on the patient's back to assist with skin markings and needle insertion trajectory for CT-guided LSB.

Abbreviations: CT, computed tomography; LSB, lumbar sympathetic blockade.

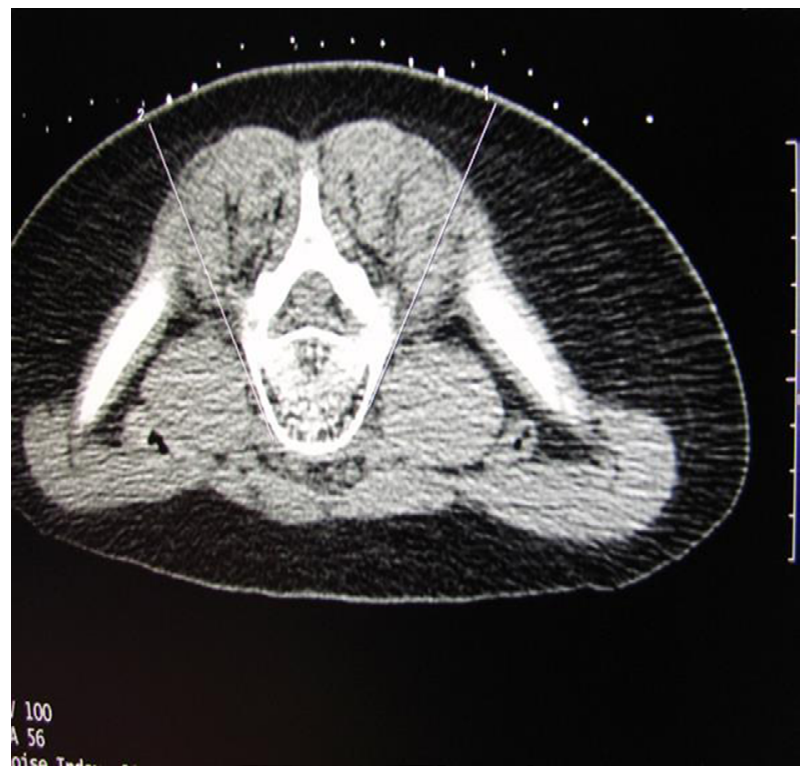

Figure 7 Radiographic image of the indicators from the marking grid, which are seen externally to the patient, and needle trajectory as seen with axial CT imaging. Abbreviation: CT, computed tomography.

triamcinolone (40 mg), bupivacaine $0.25 \%(10 \mathrm{~mL})$, and clonidine $(40 \mu \mathrm{g})$ was injected along each side. The needles were flushed with $5 \mathrm{~mL}$ of preservative free saline. A series of four, CT-guided LSBs were performed over a 12-month period. Gabapentin was changed to pregabalin secondary to the side effect of sedation. Each LSB was efficacious in providing pain relief immediately post procedure and for -3-4 months, with reduction in pain severity to $1-3 / 10$ on a numeric rating scale, along with decreased frequency of pain flare-ups and the ability to decrease the dose of gabapentin or pregabalin to a minimal, in between the blockades. She had a significant improvement in her quality of life as indicated by improved functional status, school attendance, ability to wear compression stockings and closed shoes, and participation in family activities, including hiking and zip cord lining.

\section{Discussion}

EM is a rare, chronic relapsing pain syndrome that was first reported by Graves in 1834. In 1878, Mitchell coined the term 'erythromelalgia' (erythros - red, melos - limbs, algos pain). ${ }^{1-8}$ Primary EM is most commonly caused by mutation of the voltage-gated sodium channel $\alpha$-subunit gene, $S C N 9 \mathrm{~A}$. It can be classified as either familial or sporadic, with the familial form inherited in an autosomal dominant manner. Both forms may be further classified as either juvenile or adult onset. Juvenile onset occurs prior to the age of 20 years and frequently prior to the age of 10 years. ${ }^{15-17}$ Secondary EM occurs in association with other comorbid disease processes 
such as myeloproliferative disorders, blood dyscrasias, medications, infectious agents, malignancies, Fabry's disease, connective tissue and autoimmune diseases, cellular storage diseases, and neuropathic conditions. ${ }^{18}$ Our case series reports three juvenile onset cases of EM, with two of the patients presenting before 10 years of age. All the cases were diagnosed as primary EM after ruling out secondary causes, with patient 1 and patient 3 having $S C N 9 A$ gene mutation. All the patients had lower limb symptoms primarily, while patient 2 also had involvement of the upper limb symptoms on initial presentation. As is typical of the disorder, there was a significant fluctuation in the level of pain, ranging from mild to severe with frequent symptom flare-ups. All three patients eventually developed severe debilitating pain that significantly impacted their lives, limited their activities of daily living, and resulted in significant psychological impact. Their pain was eventually refractory to multiple medical regimens, including opioids and adjuvant agents. As such, LSB was offered as a therapeutic modality.

A number of hypotheses regarding the etiology of the disorder have been postulated including vasculopathy, neuropathy, local tissue hypoxemia, and increased cellular metabolism. ${ }^{18-21}$ One of these hypotheses proposes that symptoms result from tissue hypoxemia, which is caused by the abnormal distribution of skin microvascular blood flow. $^{22}$ The contraction of precapillary sphincters and the opening of anatomical arteriovenous shunts (pathological thermoregulatory reaction) result in skin hypoxemia and hypotrophy. ${ }^{19}$ Thus cooling, a frequent therapeutic modality, works by decreasing oxygen consumption and therefore the pain. During the flare-up of symptoms, there is increased skin temperature of affected limbs, increased blood flow in the microcirculation measured by laser Doppler, and decreased tissue oxygenation measured by transcutaneous oximetry. ${ }^{20}$ Mitochondrial dysfunction has also been speculated as an underlying mechanism, although involvement limited to the extremities is difficult to explain. A neurologic mechanism is supported by studies demonstrating dysfunction of peripheral adrenergic neurons. ${ }^{21,23}$ The familial occurrence of the disorder suggests that genetic factors may play a role in the pathogenesis of the disorder with documented cases associated with alterations in membrane ion channels. ${ }^{24,25}$ The mutation causes a hyperpolarization shift during activation and decreases the threshold for single impulses and for opening of the channel. By slowing the inactivation, ion channels remain open for a longer period of time even after the activating stimulus is removed. This may explain why intense pain may persist for a prolonged period of time, which is nonproportional to the trivial stimulus. ${ }^{17}$
Patients present with intermittent heat, erythema, swelling, and pain. ${ }^{26}$ The pain is usually described as burning or piercing. It can be severe and disabling. Symptoms are usually intermittent but can be constant with changing intensity especially during flare-ups. Pain generally involves the lower extremities, occasionally affecting the hands or very rarely the ears and face. ${ }^{27}$ Symptoms are more common in the summer and can be exacerbated by heat, ambulation, physical activity, sitting, leg dependence, or wearing shoes or gloves. ${ }^{28}$ Cold temperatures may alleviate symptoms and in some cases abort an episode. Symptoms tend to lessen with cooling of the extremities by immersion in ice or cold water; exposure to air current, such as by a fan; or elevation and uncovering the affected areas. ${ }^{29}$ The symptoms may be so intense and debilitating that patients develop psychiatric or psychological changes and manifest peculiar or abnormal behaviors. These may include immersing the limbs in ice water, sleeping with the feet extended through an open window in the winter time, walking barefoot in the snow, or even placing extremities inside a refrigerator. As was noted in two (patients 1 and 3) of our patients, tissue damage (ulcers, necrosis) may occur. This is likely not the result of the primary disease process or atrophic changes, but rather occurs from tissue damage due to excessive cooling used as a therapeutic modality.

Our patients' clinical presentations match with those reported in the literature. Even mild EM can greatly affect normal function and quality of life. Patients avoid warm weather and limit their activities to cool or air-conditioned locations. Some move to cooler climates. Evening activities are avoided. Many patients cannot wear socks or closed shoes even in winter as also evident in our patients. In severe cases, patients become virtually housebound due to the pain. There is an increased morbidity associated with pediatric EM as the patients have difficulty with truancy, including prolonged leaves of absence from school or cessation of attendance. ${ }^{30}$ Patients who are able to attend school regularly alter their activities to alleviate or prevent symptoms. ${ }^{30}$ Removing socks or shoes, limiting physical activity, or avoiding participation in physical education or sports is common. Standing and even sitting with the legs in a dependent position becomes increasingly intolerable. Sleep is severely disturbed, and psychological problems including anxiety, depression, and suicidal tendencies can develop. ${ }^{30}$

The diagnosis begins with the presence of the three primary signs and symptoms (red, hot, and painful extremities) and is supported by aggravation of symptoms in response to warmth, relief by cold, and unresponsiveness to other therapies. ${ }^{30-33}$ These have been grouped in what is known as Thompson's criteria: 1) burning pain of the extremities, 
2) aggravation of pain by warmth, 3) pain relieved by cold, 4) erythema of affected skin, and 5) increased temperature of affected skin. There are no characteristic histopathologic changes noted on tissue biopsy. ${ }^{34,35}$ The symptoms are usually symmetrical and more often involve the lower extremities, and females are more often affected than males. Although our case series includes two males, given a very small sample size, our case series does not necessarily challenge or confirm any sex predominance of this disorder.

The reported treatment approaches are varied including aspirin (generally for cases associated with primary thrombocytosis or elevated platelet counts), selective serotonin reuptake inhibitors, venlafaxine, tricyclic antidepressant agents, gabapentin, pregabalin, calcium channel antagonists (nifedipine, diltiazem), beta-adrenergic antagonists, opioids, mexiletine, and lidocaine. ${ }^{36-41}$ In refractory cases, IV infusions of sodium nitroprusside or adenosine as well as epidural infusions of bupivacaine and lidocaine have resulted in remission of symptoms. ${ }^{39-43}$ Unfortunately, these medication regimens are not universally effective and do not provide long-lasting pain relief in the majority of patients. These issues were noted in all three of our patients with limited or short-lived responses to medical therapies.

As overactivity of the sympathetic nervous has been postulated as playing a primary or secondary role in the genesis of the disorder, surgical sympathectomy or sympathetic blockade has also been used as a therapeutic modality for the disorder. ${ }^{7,32,44}{ }^{47}$ Patients with EM display vasoconstriction before reactive hyperemia. This and the diurnal nature of EM flaring may indicate autonomic involvement. The success of epidural anesthesia in some patients lends further support for the potential role of the autonomic nervous system. In
1973, Postlethwaite ${ }^{44}$ reported 'excellent' results following bilateral surgical lumbar sympathectomy in four patients with EM cases. Similar anecdotal success was reported following bilateral surgical thoracic sympathectomy in a patient with EM of the hands. ${ }^{45}$

Others have reported successful pain control following the percutaneous LSB as was performed in our patients (Table 1). ${ }^{46-49}$ We present three additional cases demonstrating the potential therapeutic role of LSB in patients who fail to respond to standard medical regimens In such cases, we would advocate the use of LSB. We performed the LSBs using CT guidance, which is now recognized as a safe and highly accurate method for needle positioning prior to blockade and has been used in adults for placement of sympathetic plexus catheters to treat complex regional pain syndrome. ${ }^{21,50,51} \mathrm{An}$ advantage of using CT guidance is the precision in localization and control of the needle tip, which is especially important in children and thin patients, due to the relative paucity of retroperitoneal fat. ${ }^{50,51}$ Use of CT guidance is suggested to ensure precision of the needle placement. As such, a failure of therapeutic benefit after CT-guided LSB likely indicates nonsympathetically mediated pain mechanisms, rather than failure of the procedural technique. We used clonidine and triamcinolone as adjuvants to the local anesthetic agents. Clonidine, an $\alpha_{2}$-adrenoceptor agonist, has both anestheticand analgesic-sparing effects, and when added to local anesthetic agents it may enhance peripheral and central neural blockade due to its local and central analgesic effects. Given these mechanisms, clonidine has been used in chronic pain conditions including neuropathic and sympathetically maintained pain. ${ }^{52,53}$ The addition of a corticosteroid, triamcinolone, may add additional long-term therapeutic benefit.

Table I Previous reports of lumbar sympathetic blockade for EM

\begin{tabular}{|c|c|c|c|}
\hline References & Patient demographics & LSB technique & Results \\
\hline Seishima et $\mathrm{al}^{46}$ & $\begin{array}{l}\text { A 59-year-old Japanese man with } \\
\text { secondary EM and myasthenia } \\
\text { gravis }\end{array}$ & $\begin{array}{l}\text { Right neurolytic LSB at L4 with } \\
\text { ethanol followed by a left LSB after } \\
\text { I week }\end{array}$ & $\begin{array}{l}\text { Immediate resolution of severe pain for } 9 \text { months; skin } \\
\text { ulcers also disappeared in I-2 months after the blockade }\end{array}$ \\
\hline Bang et $\mathrm{al}^{47}$ & $\begin{array}{l}\text { A I2-year-old girl with primary } \\
\text { EM involving both lower } \\
\text { extremities }\end{array}$ & $\begin{array}{l}\text { Fluoroscopic-guided, right LSB } \\
\text { at L3 with I\% lidocaine and } \\
\text { triamcinolone followed by a left } \\
\text { LSB after I week }\end{array}$ & $\begin{array}{l}\text { Reduction in pain scores from } 5 \text { to } 3 \mathrm{I} \text { week after the } \\
\text { second blockade. Other outcomes included improved } \\
\text { comfort, ability to ambulate, improved and reduced need } \\
\text { for frequent immersion of feet in cold water }\end{array}$ \\
\hline Zhang et $\mathrm{al}^{48}$ & $\begin{array}{l}\text { A I5-year-old girl adolescent } \\
\text { with primary EM. RII50W } \\
\text { polymorphism in SCN9A }\end{array}$ & $\begin{array}{l}\text { Bilateral chemical lumbar } \\
\text { sympathectomy using } 5 \% \text { phenol } \\
\text { in aqueous solution at the L3-L4 } \\
\text { ganglia was performed with } \\
\text { radiographic guidance }\end{array}$ & $\begin{array}{l}\text { Immediate pain reduction (50\%) was achieved after } \\
\text { LSB. Burning pain, erythema, and swelling in the lower } \\
\text { legs disappeared in } 4 \text { days. Skin ulcerations healed in } \\
\text { I month. The patient resumed normal exercise } 5 \text { months } \\
\text { after LSB and there were no relapses for } 5 \text { years }\end{array}$ \\
\hline Cerci et $\mathrm{al}^{49}$ & $\begin{array}{l}\text { A } 70 \text {-year-old woman with EM } \\
\text { and worsening symptoms after } \\
\text { chemotherapy for bladder cancer }\end{array}$ & $\begin{array}{l}\text { Fluoroscopy-guided, LSB at L3 } \\
\text { with } 2 \% \text { chloroprocaine and } \\
0.375 \% \text { bupivacaine }\end{array}$ & $\begin{array}{l}\text { Significant improvement of pain and eventual } \\
\text { near-complete resolution of skin ulcers }\end{array}$ \\
\hline
\end{tabular}

Abbreviations: EM, erythromelalgia; LSB, lumbar sympathetic blockade. 
Corticosteroids may interact with GABA receptors and thus control neural excitability through a stabilizing effect on membranes, modification of nervous conduction, and membrane hyperpolarization. Slow-release formulations are generally used (methylprednisolone acetate or triamcinolone diacetate) in combination with local anesthetic agents. ${ }^{54}$

\section{Conclusion}

EM is a rare disorder that can cause severe pain and disability even in its moderate forms. It may occur as a primary disease process or a secondary event in association with other comorbid conditions. There are several proposed pathophysiologic mechanisms that explain in part the large number of therapies that have been advocated and the variability in responses to these clinical treatments. Treatment methods have considerably improved over recent years, but treating EM still remains challenging in a significant number of patients. The severity of symptoms, along with its functional and behavioral impact particularly in the pediatric population, makes early management necessary. When medical therapies fail, LSB has anecdotally been associated with a decrease in symptoms and may induce remission in certain patients. We describe three case reports with successful use of CT-guided LSB in the management of refractory pain in juvenile primary EM. Based on the limited evidence in the literature, our small case series, and a need for skilled personnel performing the procedure, it may be difficult to make any definite recommendations as to the timing for when an LSB should be included as a therapeutic option. However, it should be considered as a treatment option in the management of EM pain that has been refractory to medical treatments.

\section{Acknowledgments}

One of the cases included in this article was presented as a poster presentation as a single case report at 'Pediatric Anesthesiology 2013', the winter annual meeting for the Society for Pediatric Anesthesia held in Las Vegas in March 2013 with interim findings. The poster's abstract was published online as 'Poster Abstracts': http://www2.peds anesthesia.org/meetings/2013winter/posters/uploads/445-P1-102.pdf.

\section{Disclosure}

AK, MR, PSW, and JDT certify that they have no affiliations with or involvement in any organization or entity with any financial or nonfinancial interest in the subject matter or materials discussed in this article. The authors report no other conflicts of interest in this work.

\section{References}

1. Reed KB, Davis MD. Incidence of erythromelalgia: a population-based study in Olmsted County, Minnesota. J Eur Acad Dermatol Venereol. 2009;23(1):13-15.

2. Luo DQ, Zhao YK, Xu QF, et al. Recurrent facial erythema with burning sensation and increased temperature: a variant of erythromelalgia or a new entity? Case report. Pain Med. 2014;15(6):1007-1010.

3. Johnson E, Iyer P, Eanes A, Zolnoun D. Erythema and burning pain in the vulva: a possible phenotype of erythromelalgia. Case Rep Med. 2011;2011:374167.

4. Ramirez CC, Kirsner RS. A refractory case of erythromelalgia involving the ears. Am J Otolaryngol. 2004;25(4):251-254.

5. Brill TJ, Funk B, Thaçi D, Kaufmann R. Red ear syndrome and auricular erythromelalgia: the same condition? Clin Exp Dermatol. 2009;34(8):e626-e628.

6. Davis MDP, O'Fallon MW, Rogers RS, et al. Natural history of erythromelalgia: presentation and outcome in 169 patients. Arch Dermatol. 2000;136:330-336.

7. Zoppi M, Zamponi A, Pagni E, Buoncristiano U. A way to understand erythromelalgia. J Auton New Syst. 1985;13(1):85-89.

8. Mitchell SW. Clinical lecture on certain painful affections of the feet. Philadelphia Med Times. 1872;3:81-113.

9. Smith LA, Allen EV. Erythermalgia (erythromelalgia) of the extremities: a syndrome characterized by redness, heat, and pain. Am Heart J. 1938;161:75-88.

10. Mork C, Asker CL, Salerud EG, Kvernebo K. Microvascular arteriovenous shunting is a probable pathogenetic mechanism in erythromelalgia. J Invest Dermatol. 2000;114(4):643-646.

11. Mørk C, Kvernebo K, Asker CL, Salerud EG. Reduced skin capillary density during attacks of erythromelalgia implies arteriovenous shunting as pathogenetic mechanism. J Invest Dermatol. 2002;119(4): 949-953.

12. Davis MD, Sandroni P, Rooke TW, Low PA. Erythromelalgia: vasculopathy, neuropathy, or both? A prospective study of vascular and neurophysiologic studies in erythromelalgia. Arch Dermatol. 2003;139(10): 1337-1343.

13. Littleford RC, Khan F, Belch JJ. Impaired skin vasomotor reflexes in patients with erythromelalgia. Clin Sci (Lond). 1999;96(5): 507-512.

14. Mork C, Kalgaard OL, Kvernebo K. Impaired neurogenic control of skin perfusion in erythromelalgia. J Invest Dermatol. 2002;118(4):699-703.

15. Han C, Rush AM, Dib-Hajj SD, et al. Sporadic onset of erythermalgia: a gain-of-function mutation in Nav1.7. Ann Neurol. 2006;59(3): $553-558$.

16. Novella SP, Hisama FM, Dib-Hajj SD, Waxman SG. A case of inherited erythromelalgia. Nat Clin Pract Neurol. 2007;3(4):229-234.

17. Dib-Hajj SD, Rush AM, Cummins TR, et al. Gain-of-function mutation in Nav1.7 in familial erythromelalgia induces bursting of sensory neurons. Brain. 2005;128(pt 8):1847-1854.

18. Naas JE. Secondary erythromelalgia. JAm Podiatr MedAssoc. 2002;92: 472-474.

19. Mitchell SW. On a rare vaso-motor neurosis of extremities and on maladies with which it may be confounded. Am J Med Sci. 1878;76:17-36.

20. Kvernebo K. Erythromelalgia: a condition caused by microvascular arteriovenous shunting. J Vasc Dis Suppl. 1998;51:1-39.

21. Littleford RC, Khan F, Belch JJ. Skin perfusion in patients with erythromelalgia. Eur J Clin Invest. 1999;29(7):588-593.

22. Uno H, Parker F. Autonomic innervation of the skin in primary erythromelalgia. Arch Dermatol. 1983;119:65-71.

23. Herkovitz S, Loh F, Berger AR, Kucherov M. Erythromelalgia: association with hereditary sensory neuropathy and response to amitriptyline. Neurology. 1993;43:621-623.

24. Yang Y, Wang Y, Li S, et al. Mutations in SCN9A, encoding a sodium channel alpha subunit, in patients with primary erythromelalgia. $J$ Med Genet. 2004;41:171-174.

25. Waxman SG, Dib-Hajj S. Erythromelalgia: molecular basis for an inherited pain syndrome. Trends Mol Med. 2005;11:555-562. 
26. Albuquerque LG, França ER, Kozmhinsky V, Querino MC, Morais AG. Primary erythromelalgia: case report. Ann Bras Dermatol. 2011;86:131-134.

27. Davis MD, O'Fallon WM, Rogers RS 3rd, Rooke TW. Natural history of erythromelalgia: presentation and outcome in 168 patients. Arch Dermatol. 2000;136(3):330-336.

28. Thompson GH, Hahn G, Rang M. Erythromelalgia. Clin Orthop Relat Res. 1979;144:249-254.

29. Kvernebo K. Erythromelalgia: a condition caused by microvascular arteriovenous shunting. J Vasc Dis Suppl. 1998;51:1-39.

30. Cook-Norris RH, Tollefson MM, Cruz-Inigo AE, Sandroni P, Davis MD, Davis DM. Pediatric erythromelalgia: a retrospective review of 32 cases evaluated at Mayo Clinic over a 37-year period. J Am Acad Dermatol. 2012;66(3):416-423.

31. Cohen JS. Erythromelalgia: new theories and new therapies. J Am Acad Dermatol. 2000;43(5 pt 1):841-847.

32. Mork C, Kvernebo K. Erythromelalgia - a mysterious condition? Arch Dermatol. 2000;136:406-409.

33. Davis MD, O'Fallon WM, Rogers RS 3rd, Rooke TW. Natural history of erythromelalgia: presentation and outcome in 168 patients. Arch Dermatol. 2000;136(3):330-336.

34. Davis MD, Weenig RH, Genebriera J, Wendelschafer-Crabb G, Kennedy WR, Sandroni P. Histopathologic findings in primary erythromelalgia are nonspecific: special studies show a decrease in small nerve fiber density. J Am Acad Dermatol. 2006;55(3):519-522.

35. Waxman SG, Dib-Haff SD. Erythromelalgia: a hereditary pain syndrome enters the molecular era. Ann Neurol. 2005;57(6):785-788.

36. DiCaudo DJ, Kelley LA. Alleviation of erythromelalgia with venlafaxine. Arch Dermatol. 2004;140:621-623.

37. Firmin D, Roguedas A, Greco M, et al. Treatment of familial erythromelalgia with venlafaxine. J Eur Acad Dermatol Venereol. 2007;21: 836-837.

38. Davis MD, Sandroni P. Lidocaine patch for pain of erythromelalgia. Arch Dermatol. 2002;138:17-19.

39. Chan MK, Tucker AT, Madden S, Golding CE, Atherton DJ, Dillon MJ. Erythromelalgia: an endothelial disorder responsive to sodium nitroprusside. Arch Dis Child. 2002;87(3):229-230.

40. Kuhnert SM, Phillips WJ, Davis MD. Lidocaine and mexiletine therapy for erythromelalgia. Arch Dermatol. 1999;135:1447-1449.
41. Jang HS, Jung D, Kim S, et al. A case of primary erythromelalgia improved by mexiletine. Br J Dermatol. 2004;151:708-710.

42. Stricker LJ, Green CR. Resolution of refractory symptoms of secondary erythermalgia with intermittent epidural bupivacaine. Reg Anesth Pain Med. 2001;26(5):488-490.

43. Lindblom U, Nordfors LO, Sollevi A, Sydow O. Adenosine for pain relief in a patient with intractable secondary erythromelalgia. Eur $J$ Pain. 1997;1(4):299-302.

44. Postlethwaite JC. Lumbar sympathectomy. Br J Surg. 1973;60:878-879.

45. Shiga T, Sakamoto A, Koizumi K, Ogawa R. Endoscopic thoracic sympathectomy for primary erythromelalgia in the upper extremities. Anesth Analg. 1999;88:865-866.

46. Seishima M, Kanoh H, Izumi T, et al. A refractory case of secondary erythermalgia successfully treated with lumbar sympathetic ganglion block. Br J Dermatol. 2000;143(4):868-872.

47. Bang YJ, Yeo JS, Kim SO, Park YH. Sympathetic block for treating primary erythromelalgia. Korean J Pain. 2010;23(1):55-59.

48. Zhang L, Wang WH, Li LF, et al. Long-term remission of primary erythermalgia with R1150W polymorphism in SCN9A after chemical lumbar sympathectomy. Eur J Dermatol. 2010;20(6):763-767.

49. Cerci FB, Kapural L, Yosipovitch G. Intractable erythromelalgia of the lower extremities successfully treated with lumbar sympathetic block. J Am Acad Dermatol. 2013;69:e270-e272.

50. Heindel W, Bernst S, Manshausen G, et al. CT guided lumbar sympathectomy: results and analysis of factors influencing the outcome. Cardiovasc Intervent Radiol. 1998;21:319-323.

51. Nordmann GR, Lauder GR, Grier DJ. Computed tomography guided lumbar sympathetic block for complex regional pain syndrome in a child: a case report and review. Eur J Pain. 2006;10(5):409-412.

52. Chen LC, Wong CS, Huh BK, et al. Repeated lumbar sympathetic blockade with lidocaine and clonidine attenuates pain in complex regional pain syndrome type 1 patients - a report of two cases. Acta Anaesthesiol Taiwan. 2006;44:113-117.

53. Pöpping DM, Elia N, Marret E, Wenk M, Tramèr MR. Clonidine as an adjuvant to local anesthetics for peripheral nerve and plexus blocks: a meta-analysis of randomized trials. Anesthesiology. 2009;111(2):406-415.

54. Slipman CW, Chow DW. Therapeutic spinal corticosteroid injections for the management of radiculopathies. Phys Med Rehabil Clin N Am. 2002;13(3):697-711.
Journal of Pain Research

\section{Publish your work in this journal}

The Journal of Pain Research is an international, peer reviewed, open access, online journal that welcomes laboratory and clinical findings in the fields of pain research and the prevention and management of pain. Original research, reviews, symposium reports, hypothesis formation and commentaries are all considered for publication

\section{Dovepress}

The manuscript management system is completely online and includes a very quick and fair peer-review system, which is all easy to use. Visit http://www.dovepress.com/testimonials.php to read real quotes from published authors. 